University of Wollongong

Research Online

Faculty of Engineering and Information

Faculty of Engineering and Information

Sciences - Papers: Part B

Sciences

2017

Performance of buried HDPE pipes - part Il: total deflection of the pipe

Min Zhou

Southeast University

Fei Wang

Southeast University

Yan Jun Du

Southeast University

Martin D. Liu

University of Wollongong, martindl@uow.edu.au

Follow this and additional works at: https://ro.uow.edu.au/eispapers1

Part of the Engineering Commons, and the Science and Technology Studies Commons

Research Online is the open access institutional repository for the University of Wollongong. For further information contact the UOW Library: research-pubs@uow.edu.au 


\title{
Performance of buried HDPE pipes - part II: total deflection of the pipe
}

\begin{abstract}
Total deflection of buried thermoplastic pipes is extensively studied in previous work as it is a service limit state specified in design standards. In this paper, two-dimensional finite-element modeling is conducted to investigate the total deflection of buried high-density polyethylene (HDPE) pipes with a special consideration of the peaking behavior. The finite-element modeling method is evaluated using the data measured in a field trial which is presented in Part I. Parametric study are conducted. It is shown that the relative flexure stiffness, the type of compactor and the unit weight of soil cover have significant effects on the total deflection of the pipe. Based on analyses of the finite-element simulation results and experimental data, two empirical formulas with five parameters are proposed to describe the total deflection of HDPE pipes in both the vertical and horizontal directions. A comprehensive comparison is made between the calculated deflections made using the proposed equations and some existing methods and the measured data from published papers. It is seen that the proposed method significantly improves the accuracy of existing methods, and it also has advantages over existing methods because it has far fewer parameters and more convenient parameter determination.

\section{Disciplines}

Engineering | Science and Technology Studies

\section{Publication Details}

Zhou, M., Wang, F., Du, Y. J. \& Liu, M. D. (2017). Performance of buried HDPE pipes - part II: total deflection of the pipe. Geosynthetics International, 24 (4), 396-407.
\end{abstract}




\title{
Performance of buried HDPE pipes - part II: total deflection of the pipe
}

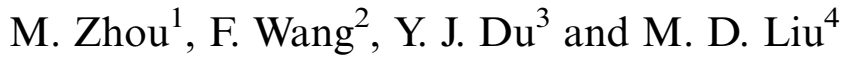 \\ ${ }^{1}$ PhD Candidate, Institute of Geotechnical Engineering, Southeast University, Nanjing 210096, Jiangsu, \\ China, E-mail:230139499@seu.edu.cn \\ ${ }^{2}$ Associate Professor, Institute of Geotechnical Engineering, Southeast University, Nanjing 210096, \\ Jiangsu, China, E-mail: feiwangseu@gmail.com (corresponding author) \\ ${ }^{3}$ Professor and Director, Institute of Geotechnical Engineering, Southeast University, Nanjing 210096, \\ Jiangsu, China, E-mail: duyanjun@seu.edu.cn (corresponding author) \\ ${ }^{4}$ Senior Lecturer, Faculty of Engineering and Information Sciences, University of Wollongong, \\ Wollongong, NSW 2522, Australia, E-mail: martindl@uow.edu.au
}

Received 13 July 2016, revised 05 December 2016, accepted 18 February 2017, published 18 April 2017

\begin{abstract}
Total deflection of buried thermoplastic pipes is extensively studied in previous work as it is a service limit state specified in design standards. In this paper, two-dimensional finite-element modeling is conducted to investigate the total deflection of buried high-density polyethylene (HDPE) pipes with a special consideration of the peaking behavior. The finite-element modeling method is evaluated using the data measured in a field trial which is presented in Part I. Parametric study are conducted. It is shown that the relative flexure stiffness, the type of compactor and the unit weight of soil cover have significant effects on the total deflection of the pipe. Based on analyses of the finite-element simulation results and experimental data, two empirical formulas with five parameters are proposed to describe the total deflection of HDPE pipes in both the vertical and horizontal directions. A comprehensive comparison is made between the calculated deflections made using the proposed equations and some existing methods and the measured data from published papers. It is seen that the proposed method significantly improves the accuracy of existing methods, and it also has advantages over existing methods because it has far fewer parameters and more convenient parameter determination.
\end{abstract}

KEYWORDS: Geosynthetics, Total deflection of pipes, Construction phase, Finite-element method, HDPE pipe, Empirical formulas

REFERENCE: Zhou, M., Wang, F., Du, Y. J. and Liu, M. D. (2017). Performance of buried HDPE pipes - part II: total deflection of the pipe. Geosynthetics International, 24, No. 4, 396-407. [http://dx. doi.org/10.1680/jgein.17.00010]

\section{INTRODUCTION}

Total deflection of flexible pipes is considered as a critical structure response in the design of buried pipes, as it is a controlling factor in pipe installation quality (Palmeira and Andrade 2010; Mehrjardi et al. 2012, 2013). Several methods have been proposed to estimate the total deflection of buried flexible pipes (Spangler 1941; Watkins and Spangler 1958; McGrath 1998a). Spangler (1941) assumed that the ratio of horizontal earth pressure on each side of the flexible pipe to the change of the pipe diameter in the horizontal direction is a constant. He proposed a well-known equation, the Iowa formula, to calculate the horizontal deflection of the pipe caused by the weight of the soil cover. In the formula, the pipe is assumed to deform as a horizontal ellipse, which is also found to be applicable in shield tunnels (Shen et al. 2014; Wu et al. 2015a, 2015b). Han et al. (2015) has proved the total deflection calculation method proposed by Spangler (1941) is also available for the deflection calculation of steel-reinforced high-density polyethylene (HDPE) pipes when the backfill is over the pipe top level. Watkins and Spangler (1958) modified the Iowa formula by replacing the modulus of passive resistance of the soil with the modulus of soil reaction, which is a real soil property. Based on the modified Iowa formula, McGrath (1998a) proposed a theoretical method that considers the pipe hoop compression to estimate the pipe deflection in the vertical direction caused by the overburden backfill.

Howard et al. (1994) found that the diameter of the flexible pipe increases in the vertical direction and decreases in the horizontal direction during soil compaction at the lateral sides of the pipe. This phenomenon is the 'peaking behaviour'. The effect of the peaking behaviour on the total deflection of pipes has been investigated in theoretical analysis, laboratory model tests, and 
field tests (Fleming et al. 1997; McGrath et al. 1999; Sargand et al. 2001, 2002, 2004; Arockiasamy et al. 2006; Masada and Sargand 2007; Wang et al. 2015). Allen and Bathurst (1994) investigated the mechanical properties of geosynthetics subjected to installation damage, and indicated that the percent of peak strength is useful to describe the degradation of modulus or strains at rupture of geosynthetic materials. The peaking behaviour can considerably reduce the total deflection of the pipe in both vertical and horizontal directions, which in turn benefits the long-term performance of the pipe (Rogers 1988; Rogers et al. 1995a, 1995b; Sargand et al. 2002; Masada and Sargand 2007; Wang et al. 2015). However, the effect of peaking behaviour on the total deflection of pipes has not been considered in the existing calculation methods, including Spangler (1941), Watkins and Spangler (1958) and McGrath (1998a, 1998b). Han et al. (2015) suggested using the sum of the peaking deflection and the deflection calculated by the Iowa formula to calculate the total deflection of steel-reinforced HDPE pipes when the pipe installation is completed. Masada and Sargand (2007) proposed a formula to calculate the peaking deflection of flexible pipes (i.e. the change of pipe diameter divided by the undeformed pipe diameter during the initial backfilling process). They pointed out that a more realistic total deflection of pipes can be obtained by superimposing the peaking deflection calculated by their formula and the deflection computed by the modified Iowa formula. However, this superimposition method may reduce the accuracy of the calculated total deflection for the following reasons: (1) the load on the pipe is calculated using the soil prism load in the modified Iowa formula outlined by AASHTO (2012). The soil arching change at the pipe top due to the peaking deflection is not considered by the soil prism load. In other words, the compaction effect on the soil arching around the flexible pipes cannot be reflected; (2) in the modified Iowa formula, the buried flexible pipes are assumed to be undeformed during the initial backfilling process. Consequently, the peaking behaviour of the pipe is ignored. Therefore, it is necessary to propose a new method for calculating the total deflection of the flexible pipe with consideration of peaking behaviour.

This paper is the second part of a study on the deflection of buried HDPE pipes. Part I of this series presents the results of the field trial and finite-element (FE) modeling on the peaking deflection. The FE modeling method employed in this study is evaluated by the measured total deflection of HDPE pipes in the field trial. The effects of pipe diameter, relative flexure stiffness (i.e. the ratio of the constrained modulus of the sidefill to the pipe stiffness), trench width, compactor type, and unit weight of the soil cover on the total deflection of the HDPE pipe are subsequently investigated. Based on the numerical results, two empirical formulas are proposed to predict the total deflection of the pipe in both the vertical and horizontal directions. The formulas are tested in light of several field cases reported in published papers. Comparisons of the calculated results using the proposed and the existing method and the measured data demonstrate the effectiveness of the proposed method.

\section{REVIEW OF EXISTING CALCULATION METHODS}

The horizontal diameter change of the pipe $(\Delta x)$ due to weight of the soil cover can be estimated by the modified Iowa equation (Watkins and Spangler 1958)

$$
\Delta x=D_{\mathrm{L}} K W_{\mathrm{c}} /\left(0.0254\left(0.149 \mathrm{PS}+0.061 E^{\prime}\right)\right)
$$

where $D_{\mathrm{L}}$ is the deflection lag factor; $K$ is the bedding constant; $E^{\prime}$ is the modulus of soil reaction $(\mathrm{kPa}) ; W_{\mathrm{c}}$ is the soil load per unit length of pipe $(\mathrm{kN} / \mathrm{m})$ which can be calculated via Equation 2; PS is the pipe stiffness $(\mathrm{kPa})$ which can be calculated via Equation 3

$$
W_{\mathrm{c}}=C_{\mathrm{d}} \gamma B D
$$

where $C_{\mathrm{d}}$ is the load coefficient, $\gamma$ is the unit weight of the cover soil $\left(\mathrm{kN} / \mathrm{m}^{3}\right), B$ is the trench width $(\mathrm{m})$, and $D$ is the diameter of the pipe $(\mathrm{m})$.

$$
\mathrm{PS}=6.72 E I / r^{3}
$$

where $E$ is the Young's modulus of the pipe material $(\mathrm{kPa})$, $I$ is the moment of inertia of pipe wall per unit length $\left(\mathrm{m}^{4} / \mathrm{m}\right)$, and $r$ is the radius of the undeformed pipe $(\mathrm{m})$.

The vertical diameter change of the pipe $(\Delta y)$ due to the weight of the soil cover is assumed to be equal in magnitude but opposite in direction to the horizontal deflection of the pipe calculated via the modified Iowa formula. The equation is expressed as (CECS 2004)

$$
\Delta y=-D_{\mathrm{L}} K W_{\mathrm{c}} /\left(0.0254\left(0.149 \mathrm{PS}+0.061 E^{\prime}\right)\right)
$$

Masada and Sargand (2007) propose the following equation to estimate the peaking deflection in both vertical and horizontal directions

$$
\Delta y / D=\Delta x / D=\left(4.7 P_{\mathrm{c}}+K_{0} r \gamma^{\prime}\right) / 3.874 \mathrm{PS}
$$

where $\Delta y$ is the vertical diameter change of the pipe (m); $\Delta x$ is the horizontal diameter change of the pipe (m); $P_{\mathrm{c}}$ is the lateral pressure generated by the compactor $(\mathrm{kPa}) ; K_{0}$ is the lateral earth pressure coefficient at rest; $\gamma^{\prime}$ is the unit weight of the backfill at the lateral side of the pipe $\left(\mathrm{kN} / \mathrm{m}^{3}\right)$. Masada and Sargand (2007) indicated that the total deflections of buried thermoplastic pipes can be calculated by superimposing the calculated values using Equations 1 and 5 (hereafter referred to as Method 1).

Based on the modified Iowa formula, McGrath (1998a) proposed an equation to calculate the vertical diameter decrease $(\Delta y)$ due to the weight of the soil cover considering the pipe hoop compression, which is expressed as

$$
\begin{aligned}
\Delta y= & W_{\mathrm{c}} /\left(0.0254\left(\mathrm{PS}_{\mathrm{H}}+0.57 E^{\prime}\right)\right) \\
& +D_{\mathrm{L}} K W_{\mathrm{c}} /\left(0.0254\left(0.149 \mathrm{PS}+0.061 E^{\prime}\right)\right)
\end{aligned}
$$

where $\mathrm{PS}_{\mathrm{H}}$ is the pipe hoop stiffness $(\mathrm{kPa})$ which can be calculated by Equation 7.

$$
\mathrm{PS}_{\mathrm{H}}=E A / r
$$

where $A$ is the cross sectional area of the pipe wall per unit length $\left(\mathrm{m}^{2} / \mathrm{m}\right)$. 
According to the method proposed by Masada and Sargand (2007), the vertical deflection of buried thermoplastic pipes can be calculated by superimposing the values of those calculated by using Equations 5 and 6 (hereafter referred to as Method 2).

The AASHTO (2012) design method for estimating the total vertical pipe deflection is expressed as

$$
\Delta y=D_{\mathrm{L}} K P_{\mathrm{sp}} D /\left(0.149 \mathrm{PS}+0.061 M_{E}\right)+\varepsilon_{\mathrm{sc}} D
$$

where $P_{\mathrm{sp}}$ is the soil prism pressure $(\mathrm{kPa})$, which is expressed by Equation $9 ; M_{\mathrm{S}}$ is the constrained soil modulus $(\mathrm{kPa})$; and $\varepsilon_{\mathrm{sc}}$ is the service compressive strain, which is calculated by Equation 10.

$$
P_{\mathrm{sp}}=\gamma(H+0.11 D)
$$

where $H$ is the soil cover thickness (m).

$$
\varepsilon_{\mathrm{sc}}=P_{\mathrm{s}} / \mathrm{PS}_{\mathrm{H}}
$$

where $P_{\mathrm{s}}$ is design service pressure $(\mathrm{kPa})$.

Using the linear regression method, Wang et al. (2015) proposed the following empirical equations based on the field data for the total deflection of

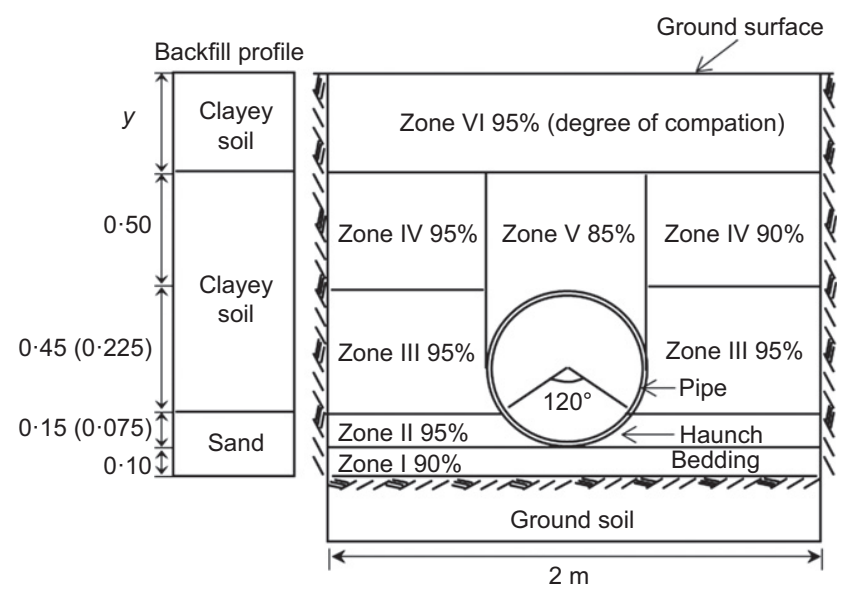

Figure 1. Required degree of compaction of the backfill around the buried HDPE pipe (unit: $\mathrm{m}$; $y$ : soil cover thicknesses. The numbers in brackets represent the dimensions of the pipe with a diameter of $0.3 \mathrm{~m}$ )
HDPE pipe (hereafter referred to as Method 4)

$$
\begin{aligned}
& \Delta y / D=(-0.2 H+0.43) / 100 \\
& \Delta x / D=(-0.18 H+0.44) / 100
\end{aligned}
$$

\section{VALIDATION OF NUMERICAL MODEL}

Two-dimensional finite-element (2DFE) modeling was conducted to investigate the total deflection of the HDPE pipe in both the vertical and horizontal directions considering the effect of the peaking behaviour. A field trial was conducted to provide data to evaluate the FE modeling method. The degree of compaction for each zone of soil cover according to ASTM D1556-07 is shown in Figure 1. Details of the field trial and FE modeling with respect to the initial backfilling process (i.e. when the soil was backfilled up to the pipe top level) are presented in Part I (Zhou et al. 2017). In this study, the soil cover (i.e. Zone IV to VI in Figure 2) is activated layer by layer to investigate the effect of the burial depth on the total deflection of the pipe. Table 1 tabulates the total deflection of HDPE pipes measured in the field trial and computed using the FE modeling. The FE results agree well with the measured ones, with relative errors of less than $10 \%$ for both the vertical and the horizontal directions. It is seen that the FE model adopted in this study is effective to estimate the total deflection of the HDPE pipe.

\section{PARAMETRIC STUDIES}

Because the total deflection of the pipe is influenced significantly by the peaking behaviour (Fleming et al. 1997; McGrath et al. 1999, 2002; Masada and Sargand 2007; Wang et al. 2015), the same influencing factors as those discussed in Part I including the pipe diameter, trench width, relative flexure stiffness, and compactor type are also adopted in the parametric studies of this paper. In addition, the effect of the unit weight of the soil cover on the total deflection is investigated, as the pipe deflection is mainly caused by overburden pressure when the backfill is higher than the pipe top level. Compacted native soil is commonly used as the backfilled material above the pipe (e.g. clayey soil, sand or crushed stone). Unit weights of

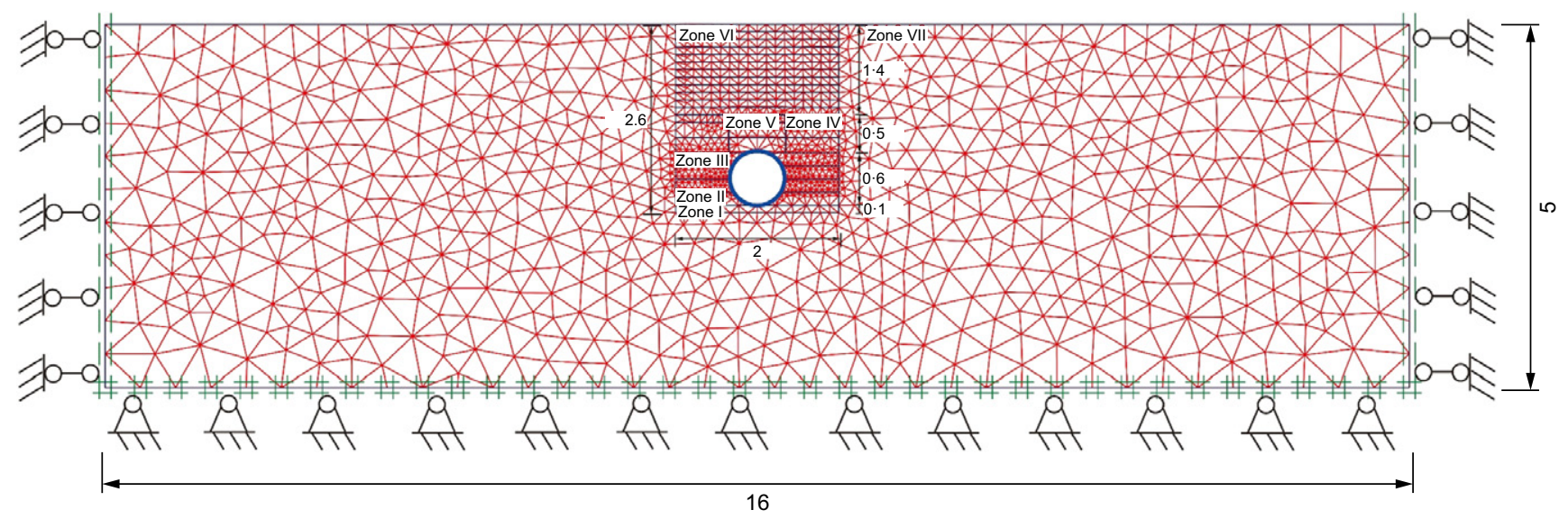

Figure 2. FE model (Zone I and II: air-dried sand; Zone III to VI: backfilled excavated in-situ soil; Zone VII: in-situ soil; unit: m) 
Table 1. Total deflection of HDPE pipes measured and computed

\begin{tabular}{|c|c|c|c|c|c|c|c|c|c|}
\hline \multirow[t]{2}{*}{ Pipe ID } & \multirow[t]{2}{*}{$\begin{array}{c}\text { Pipe } \\
\text { diameter (m) }\end{array}$} & \multirow[t]{2}{*}{$\begin{array}{c}\text { Degree of } \\
\text { compaction }(\%)\end{array}$} & \multirow[t]{2}{*}{$\begin{array}{l}\text { Soil cover } \\
\text { thickness (m) }\end{array}$} & \multicolumn{2}{|c|}{ FE results } & \multicolumn{2}{|c|}{ Field data } & \multicolumn{2}{|c|}{$\begin{array}{l}\text { Relative errors }(\mathrm{FE} \\
\text { results-Field data)/ } \\
\text { FE results } \times 100 \%\end{array}$} \\
\hline & & & & $\mathrm{d} y(\%)$ & $\mathrm{d} x(\%)$ & $\mathrm{d} y(\%)$ & $\mathrm{d} x(\%)$ & $\mathrm{d} y(\%)$ & $\mathrm{d} x(\%)$ \\
\hline \multirow[t]{3}{*}{$\mathrm{P} 1$} & \multirow[t]{3}{*}{0.3} & \multirow[t]{3}{*}{95} & 0.3 & 0.39 & -0.36 & 0.38 & -0.37 & 2.6 & 2.8 \\
\hline & & & 0.5 & 0.30 & -0.34 & 0.31 & -0.31 & 3.3 & 9.7 \\
\hline & & & 1.0 & 0.21 & -0.25 & 0.20 & -0.23 & 5.0 & 8.7 \\
\hline \multirow[t]{4}{*}{$\mathrm{P} 2$} & \multirow[t]{4}{*}{0.6} & \multirow[t]{4}{*}{95} & 0.2 & 0.36 & -0.37 & 0.39 & -0.40 & 8.3 & 8.1 \\
\hline & & & 0.5 & 0.27 & -0.34 & 0.28 & -0.31 & 3.7 & 9.6 \\
\hline & & & 1.0 & 0.19 & -0.24 & 0.18 & -0.22 & 5.6 & 9.1 \\
\hline & & & 1.9 & 0.052 & -0.095 & 0.05 & -0.10 & 4.0 & 5.3 \\
\hline \multirow[t]{3}{*}{ P3 } & \multirow[t]{3}{*}{0.6} & \multirow[t]{3}{*}{95} & 0.4 & 0.34 & -0.35 & 0.36 & -0.37 & 5.9 & 5.7 \\
\hline & & & 0.6 & 0.28 & -0.33 & 0.30 & -0.33 & 7.1 & 3.1 \\
\hline & & & 0.9 & 0.22 & -0.29 & 0.24 & -0.27 & 9.1 & 7.4 \\
\hline
\end{tabular}

Note: $\mathrm{d} y$, vertical diameter change/un-deformed pipe diameter; $\mathrm{d} x$, horizontal diameter change/un-deformed pipe diameter. Positive represents pipe diameter decrease, while negative ones denote diameter increase.

Table 2. Parameters used in the parametric studies

\begin{tabular}{|c|c|c|c|c|c|c|c|c|}
\hline $\begin{array}{l}\text { Case } \\
\text { number }^{\mathrm{a}}\end{array}$ & $\begin{array}{c}\text { Pipe } \\
\text { diameter }(m)\end{array}$ & $\begin{array}{c}\text { Pipe } \\
\text { stiffness }(\mathrm{kPa})\end{array}$ & $\begin{array}{c}\text { Sidefill } \\
\text { material }^{\mathrm{b}}\end{array}$ & $\begin{array}{c}\text { Soil } \\
\text { modulus (MPa) }\end{array}$ & $\begin{array}{c}\text { Trench } \\
\text { width }(\mathrm{m})\end{array}$ & $\begin{array}{l}\text { Kneading } \\
\text { factor }^{\mathrm{c}}\end{array}$ & $\begin{array}{l}\text { Backfill material } \\
\text { in the soil cover }\end{array}$ & $\begin{array}{l}\text { Unit weight of backfill in } \\
\text { the soil cover }\left(\mathrm{kN} / \mathrm{m}^{3}\right)\end{array}$ \\
\hline $1 *$ & 0.3 & 215 & SW85 & 2.56 & 2.0 & 1.0 & SW90 & 20 \\
\hline 2 & 0.6 & 215 & SW85 & 2.56 & 2.0 & 1.0 & SW90 & 20 \\
\hline 3 & 0.8 & 215 & SW85 & 2.56 & 2.0 & 1.0 & SW90 & 20 \\
\hline 4 & 1.2 & 215 & SW85 & 2.56 & 2.0 & 1.0 & SW90 & 20 \\
\hline 5 & 0.3 & 107 & SW85 & 2.56 & 2.0 & 1.0 & SW90 & 20 \\
\hline 6 & 0.3 & 339 & SW85 & 2.56 & 2.0 & 1.0 & SW90 & 20 \\
\hline 7 & 0.3 & 430 & SW85 & 2.56 & 2.0 & 1.0 & SW90 & 20 \\
\hline 8 & 0.3 & 672 & SW85 & 2.56 & 2.0 & 1.0 & SW90 & 20 \\
\hline 9 & 0.3 & 860 & SW85 & 2.56 & 2.0 & 1.0 & SW90 & 20 \\
\hline 10 & 0.3 & 215 & SW95 & 6.44 & 2.0 & 1.0 & SW90 & 20 \\
\hline 11 & 0.3 & 215 & CL95 & 1.44 & 2.0 & 1.0 & SW90 & 20 \\
\hline 12 & 0.3 & 215 & SW85 & 2.56 & 0.8 & 1.0 & SW90 & 20 \\
\hline 13 & 0.3 & 215 & SW85 & 2.56 & 1.2 & 1.0 & SW90 & 20 \\
\hline 14 & 0.3 & 215 & SW85 & 2.56 & 1.6 & 1.0 & SW90 & 20 \\
\hline 15 & 0.3 & 215 & SW85 & 2.56 & 2.0 & 2.0 & SW90 & 20 \\
\hline 16 & 0.3 & 215 & SW85 & 2.56 & 2.0 & 1.0 & SW95 & 21 \\
\hline 17 & 0.3 & 215 & SW85 & 2.56 & 2.0 & 1.0 & CL90 & 17 \\
\hline 18 & 0.3 & 215 & SW85 & 2.56 & 2.0 & 1.0 & SW85 & 15 \\
\hline
\end{tabular}

a*, baseline case.

${ }^{\mathrm{b}}$ Sidefill represents the backfill placed at the lateral sides of the pipe. SW85, well-graded sand with degree of compaction of $85 \%$; SW95, well-graded sand with degree of compaction of $95 \%$; CL95, low plasticity clay with degree of compaction of $95 \%$.

${ }^{\mathrm{c}}$ Kneading factor: $1.0=$ vibratory plate compactor; $2.0=$ rammer.

${ }^{\mathrm{d}}$ SW90, well-graded crushed stone with a degree of compaction of $90 \%$; CL90, low plasticity clay with a degree of compaction of $90 \%$.

$15 \mathrm{kN} / \mathrm{m}^{3}, 17 \mathrm{kN} / \mathrm{m}^{3}, 20 \mathrm{kN} / \mathrm{m}^{3}$, and $21 \mathrm{kN} / \mathrm{m}^{3}$ are used in the FE modeling, following the suggestion by McGrath et al. (1999) for sand with a compaction degree of $85 \%$, clayey soil with a compaction degree of $90 \%$, and crushed stone with compaction degrees of $90 \%$ and $95 \%$. Eighteen cases of computations are tabulated in Table 2.

Figures 3 and 4 present the effects of pipe diameter and trench width on the total deflection of pipes. Pipe stiffness of $215 \mathrm{kPa}$ and sidefill material of SW85 are employed to investigate the effects of the pipe diameter and trench width on the total deflection of the pipe. In Figures 3 and 4 , respectively, the trench width and pipe diameter are $2.0 \mathrm{~m}$ and $0.3 \mathrm{~m}$. It is seen that the total pipe deflection decreases both in the vertical and horizontal directions with the increase of soil cover thickness (i.e. $H$ ). However, the vertical deflection varies only from $3 \%$ to $6 \%$ when the pipe diameter increases from $0.3 \mathrm{~m}$ to $1.2 \mathrm{~m}$. Meanwhile, the horizontal deflection varies from $4 \%$ to $7 \%$. Similarly, the variation is in the range of $2 \%$ to $5 \%$ when the trench width increases from $0.8 \mathrm{~m}$ to $2.0 \mathrm{~m}$. It is thus concluded that the influences of the pipe diameter and the trench width on the total deflection are insignificant.

Figure 5 shows the effect of pipe stiffness (PS) on the total deflection of the pipe. When the PS increases from $107 \mathrm{kPa}$ to $860 \mathrm{kPa}$ (i.e. the relative flexure stiffness $\left(S_{\mathrm{f}}\right)$ decreases from 231 to 29 ), the total deflection decreases from $35 \%$ to $56 \%$ for the vertical deflection, and $42 \%$ to $64 \%$ for the horizontal deflection in spite of a constant passive lateral earth pressure coefficient, $K_{\mathrm{p}}$. Figure 6 illustrates the effect of the sidefill type and the degree of 
compaction on the total deflection of the pipe. It was found that the differences in both the vertical and the horizontal deflections were insignificant (i.e. $2 \%$ to $4 \%$ ) between the pipes embedded in backfilled soil with similar relative flexure stiffness (i.e. lean clay with a compaction

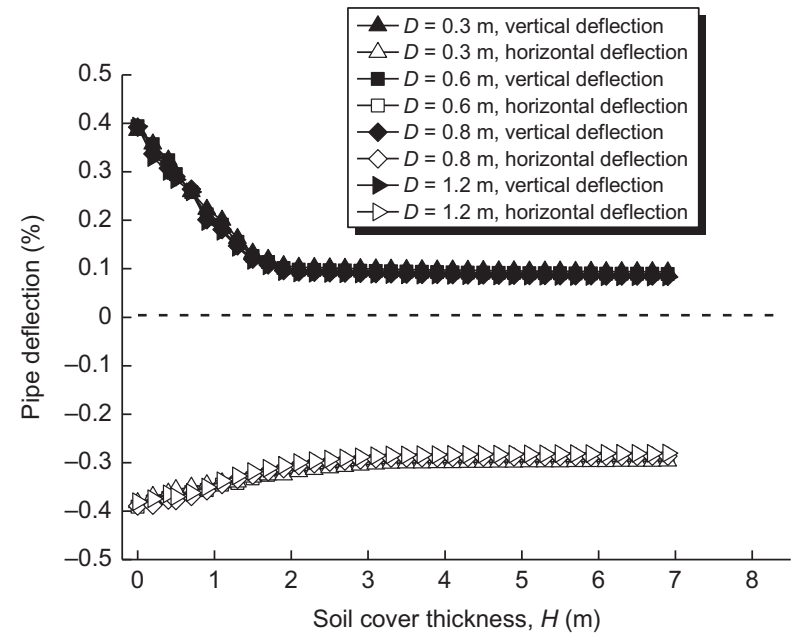

Figure 3. Effect of pipe diameter $(D)$ on the pipe deflections via FE simulations

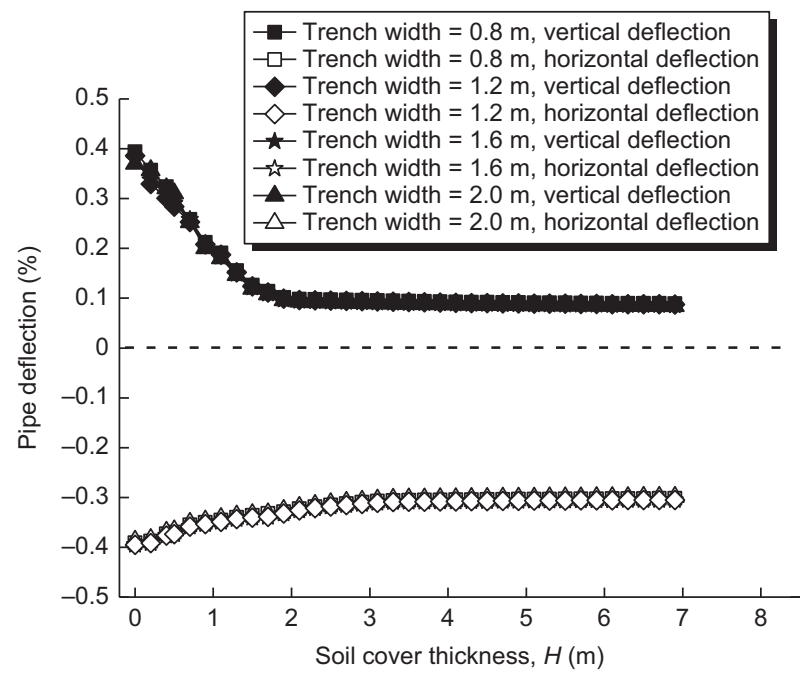

Figure 4. Effect of trench width on the pipe deflections via FE simulations

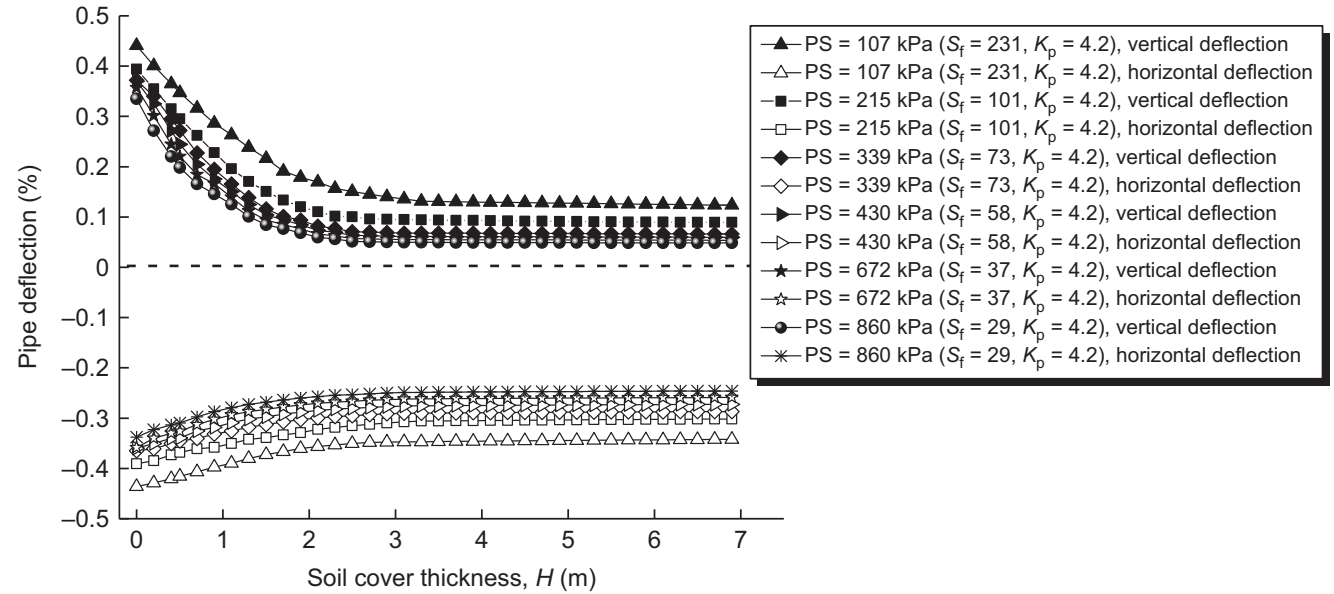

Figure 5. Effect of pipe stiffness (PS) on the pipe deflections via FE simulations degree of 95\% (CL95, $\left.S_{\mathrm{f}}=115\right)$ and well-graded sand with a compaction degree of $\left.85 \%\left(\mathrm{SW} 85, S_{\mathrm{f}}=101\right)\right)$, even with a big difference of $K_{\mathrm{p}}$ value (SW85 (4.2) and CL95 (2.77)). The vertical and horizontal total deflections of the pipe buried in well-graded sand with a compaction degree of $95 \%\left(\mathrm{SW} 95, S_{\mathrm{f}}=431\right)$ are $35 \%$ to $83 \%$ and $30 \%$ to $75 \%$ higher than those of the pipe buried in CL95 $\left(S_{\mathrm{f}}=115\right)$, respectively. Figures 5 and 6 show that buried pipe of a relatively higher flexure stiffness material yields a larger total deflection at a given soil cover thickness. It was concluded that $S_{\mathrm{f}}$ is a crucial design parameter for the total deflection of the pipe.

Figure 7 presents the effect of the compactor type (i.e. vibratory plate and rammer compactor) on the total deflection of the pipe. The vertical and horizontal deflections of the pipe for the cases using a rammer compactor were 2.3 to 2.5 and 2.2 to 2.4 times those with the vibratory plate compactor employed, respectively. The average ratio of pipe deflections generated by the rammer to those by the vibratory plate compactor was 2.4 . It was seen that the compactor type has a significant effect on the total deflection of the pipe.

Figure 8 addresses the effect of the unit weight of soil cover $(\gamma)$ on the total deflection of the pipe. It was seen that the magnitudes of the pipe deflection in the vertical and horizontal directions decreased by $3 \%$ to $56 \%$ and $2 \%$ to $20 \%$ when the unit weight of the soil cover increased from $15 \mathrm{kN} / \mathrm{m}^{3}$ to $21 \mathrm{kN} / \mathrm{m}^{3}$, respectively. As a result, $\gamma$ influences significantly the total deflection of the pipe, and should be taken into consideration.

\section{PROPOSED EMPIRICAL FORMULA AND ITS VALIDATION}

\subsection{Proposed empirical formulas}

Based on the study in the above section, the following characteristics of the total deflection of the pipe are seen.

(1) The effects of relative flexure stiffness, compactor type and unit weight of the soil cover are significant, and thus should be considered in the total deflection of pipes. 


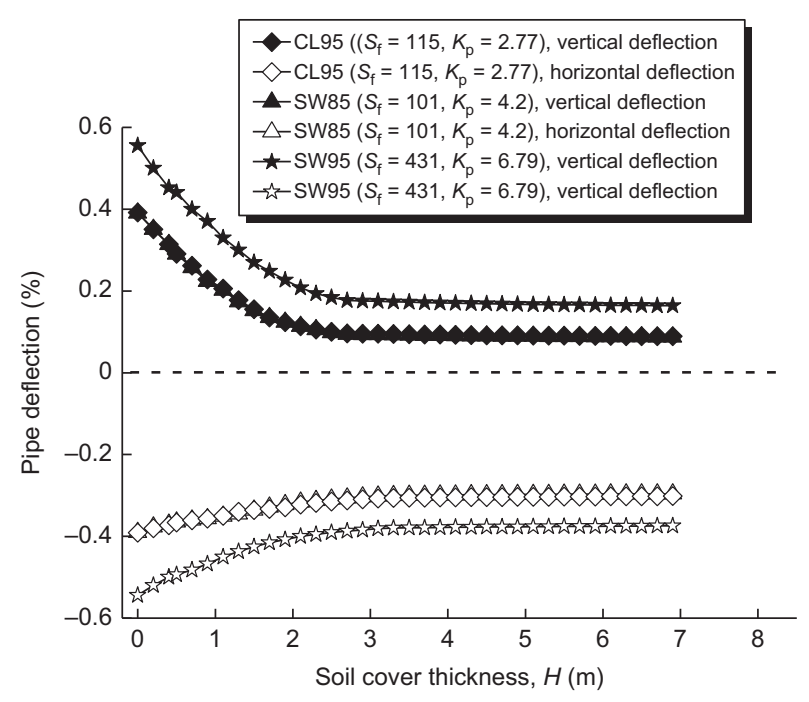

Figure 6. Effects of the sidefill type and the degree of compaction on the pipe deflections via FE simulations (CL, lean clay; SW, well-graded sand)

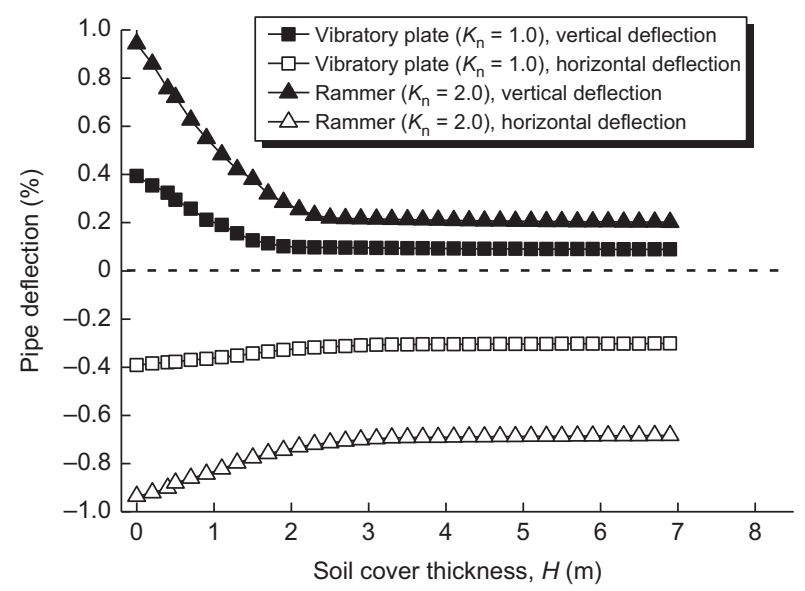

Figure 7. Effect of the compactor type on the pipe deflections via FE simulations

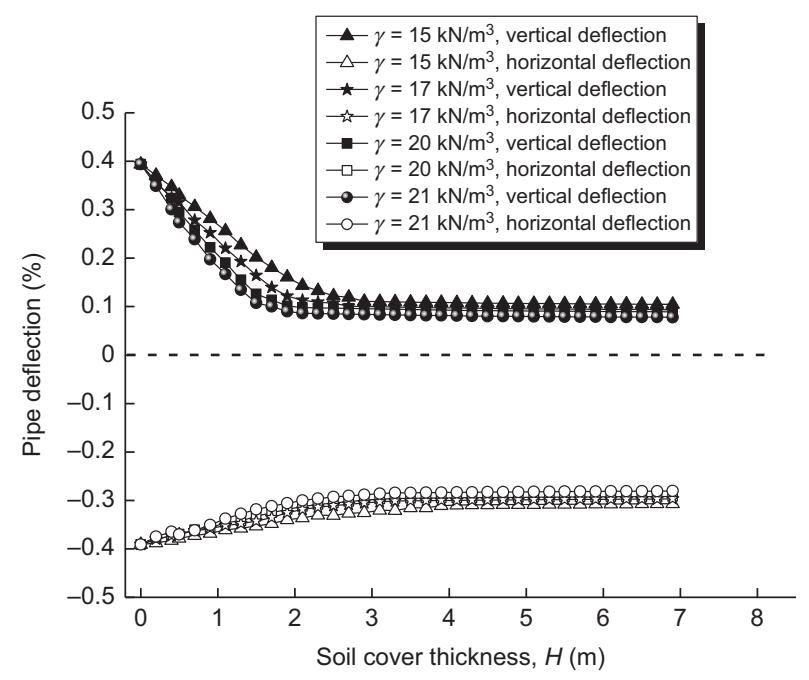

Figure 8. Effect of unit weight of the soil on the pipe deflections via FE simulations
(2) The effects of pipe diameter and trench width are insignificant, and thus can be omitted.

(3) The magnitude of total deflection in both the vertical and the horizontal directions decreases approximately exponentially with the soil cover thickness $H$.

However, the magnitude of the vertical deflection of the pipe experiences a greater decrement than the horizontal one during the construction of the soil cover. This is attributed to the circumferential shortening of the pipe during construction.

Formulas are derived using the Least-Square-Root method by interlinking the total deflection of the pipe in the vertical and the horizontal directions with relative flexure stiffness, compactor type, the unit weight of the cover soil, and the soil cover thickness, expressed as follows

$$
\begin{aligned}
\Delta y / D= & \left(-0.03 S_{\mathrm{f}}+3.4+\left(0.02 S_{\mathrm{f}}+29.6\right)\right. \\
& \times \exp (-\gamma H / 20)) \eta / 10000 \\
\Delta x / D= & \left(-0.03 S_{\mathrm{f}}+23.4+\left(0.02 S_{\mathrm{f}}+9.6\right)\right. \\
& \times \exp (-\gamma H / 20)) \eta / 10000
\end{aligned}
$$

where $\eta$ is the an empirical constant related to the compactor type, which is 1.0 and 2.4 for the vibratory plate and the rammer compaction methods, respectively. It is concluded from Figures 5 and 6 that relative flexure stiffness $\left(S_{\mathrm{f}}\right)$ has a more significant effect on the total deflection of the pipe than $K_{\mathrm{p}}$. Therefore, the $S_{\mathrm{f}}$ rather than the $K_{\mathrm{p}}$ is included in Equations 13 and 14 .

The values of the coefficient of determination $\left(R^{2}\right)$ for Equations 13 and 14 are 0.97 and 0.95 , respectively.

\subsection{Validation of proposed formulas}

McGrath et al. (1999), Arockiasamy et al. (2006) and Corey et al. (2014) conducted the field and laboratory evaluation of the total deflection of buried HDPE pipes. Their data were used to evaluate Equations 13 and 14. Figures 9-12 present the comparisons of the total deflections calculated by Method 1 (Equations 1 or 4 and 5), Method 2 (Equations 5 and 6), Method 3 AASHTO (2012) design method (Equation 8), Method 4 (Equations 11 and 12) and the proposed method (Equations 13 and 14) with the data reported by McGrath et al. (1999), Arockiasamy et al. (2006) and Corey et al. (2014) and this study, respectively. The values of the equation parameters used in the calculations are shown in Tables 3-6.

The value of the constrained soil modulus $\left(M_{\mathrm{s}}\right)$ is considered to be equal to the modulus of soil reaction $\left(E^{\prime}\right)$ in this study, as suggested by Hartley and Duncan (1987) and McGrath (1998b). The value of $D_{\mathrm{L}}$ is suggested as 1.0, where the consolidation of the backfill at the lateral sides of the pipe is not considered because of the short duration of the construction phase. The value of $K$ is selected as 0.1 for the calculation of the total deflection of the pipe, as recommended by Moser and Folkman (1990). The values of product of the active earth pressure coefficent $k$ and coefficient of friction between the backfill and trench wall $\mu$ are selected as 0.165 for cases $6,7,8$ 


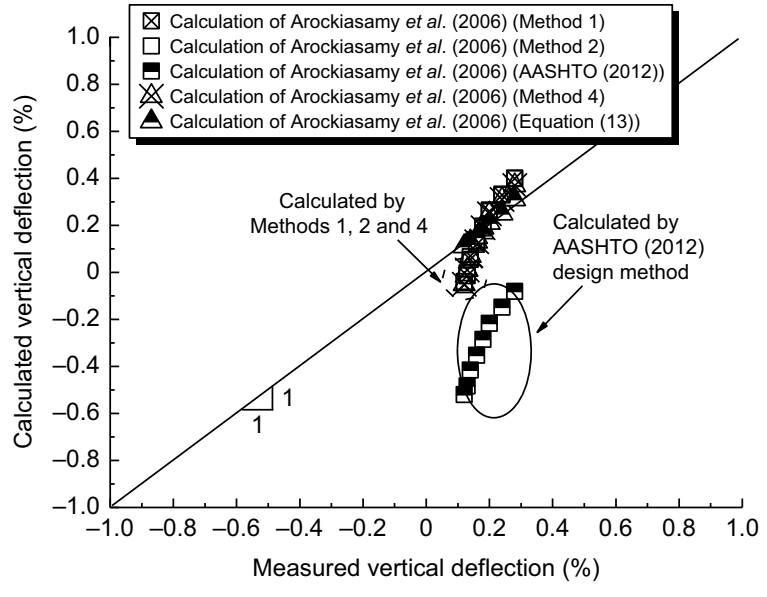

(a)

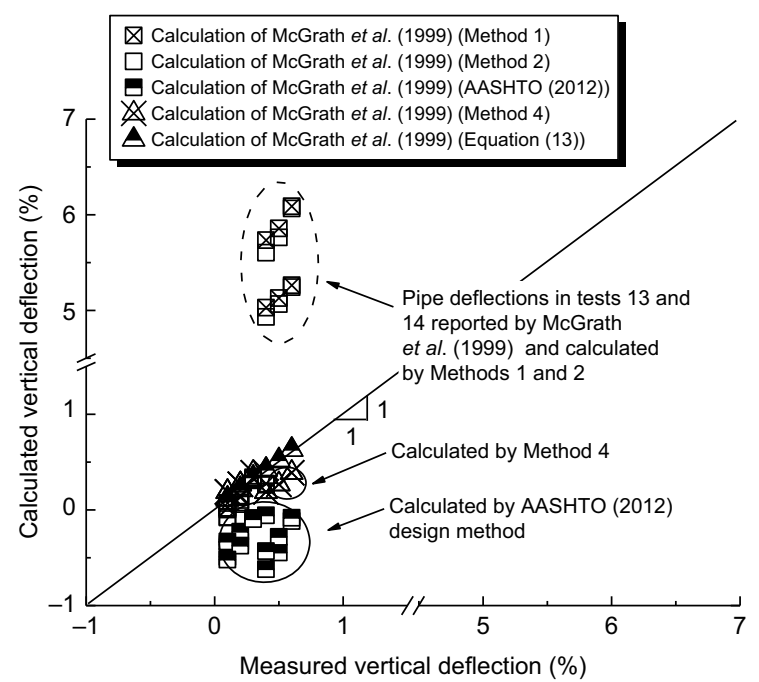

(b)

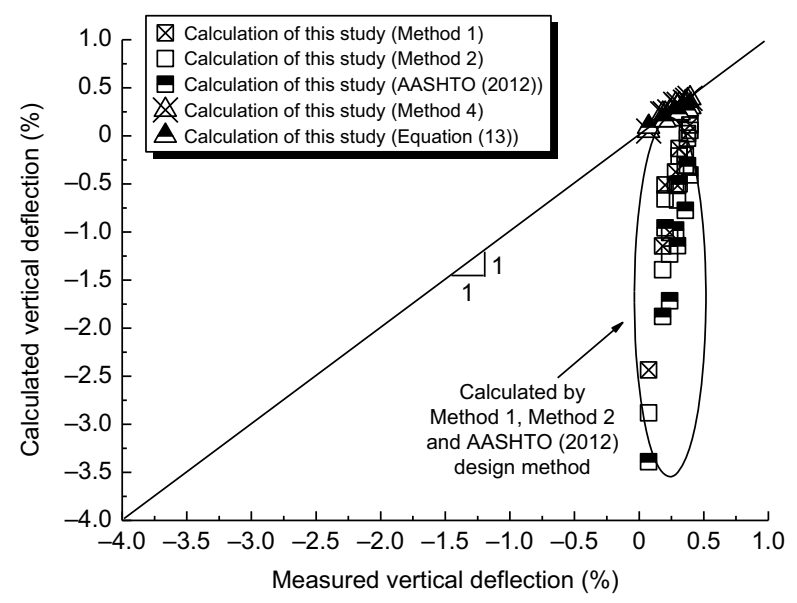

(c)

Figure 9. Comparison of the measured and the simulated vertical deflections of pipes for the vibratory plate compactor

and 14 reported by McGrath et al. (1999), the case reported by Arockiasamy et al. (2006) and the case reported by Corey et al. (2014), and as 0.1924 for cases 1, 3, 4, 9, 11 and 13 reported by McGrath et al. (1999) to calculate $C_{\mathrm{d}}$ in Equation 2, as suggested by Moser and Folkman (1990). In this study, the design service pressure $P_{\mathrm{s}}$ is taken as equal to the soil prism pressure $P_{\mathrm{sp}}$ in the AASHTO (2012) design method.

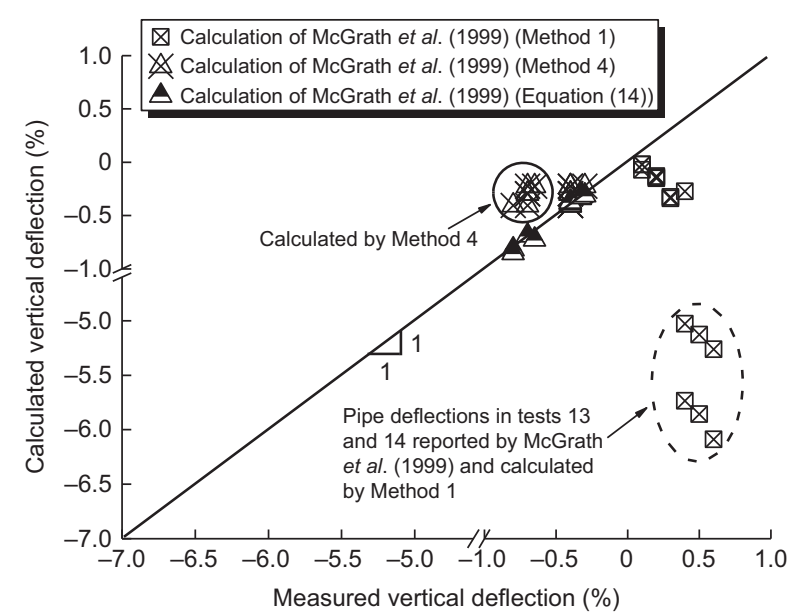

(a)

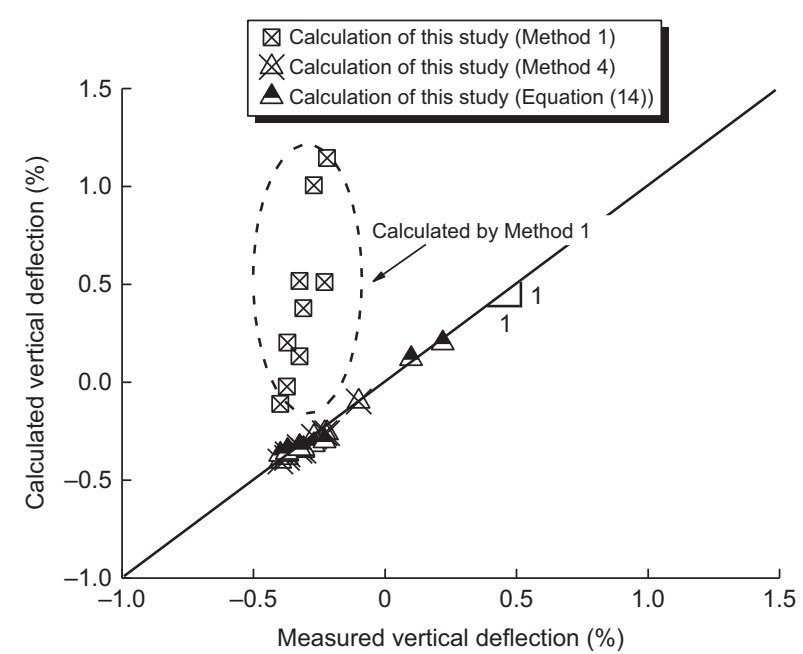

(b)

Figure 10. Comparison of the measured and the simulated horizontal deflections of pipes for the vibratory plate compactor

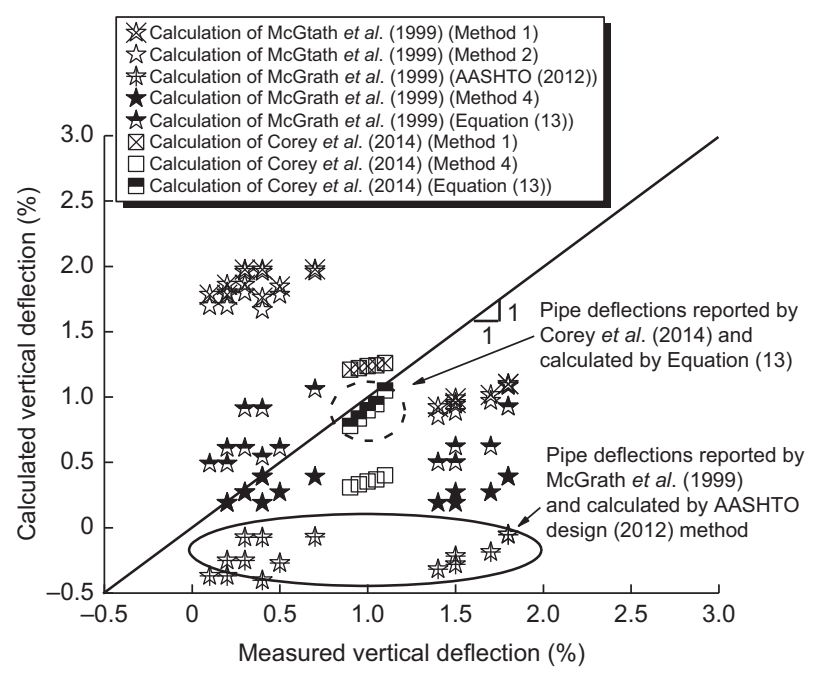

Figure 11. Comparison of the measured and simulated vertical deflections of pipes for the rammer compactor

5.2.1. Validation for cases using vibratory plate compactor Figure 9a shows that the total deflection in the vertical direction calculated by the AASHTO (2012) design method (Equation 8) is negative (i.e. the diametric 


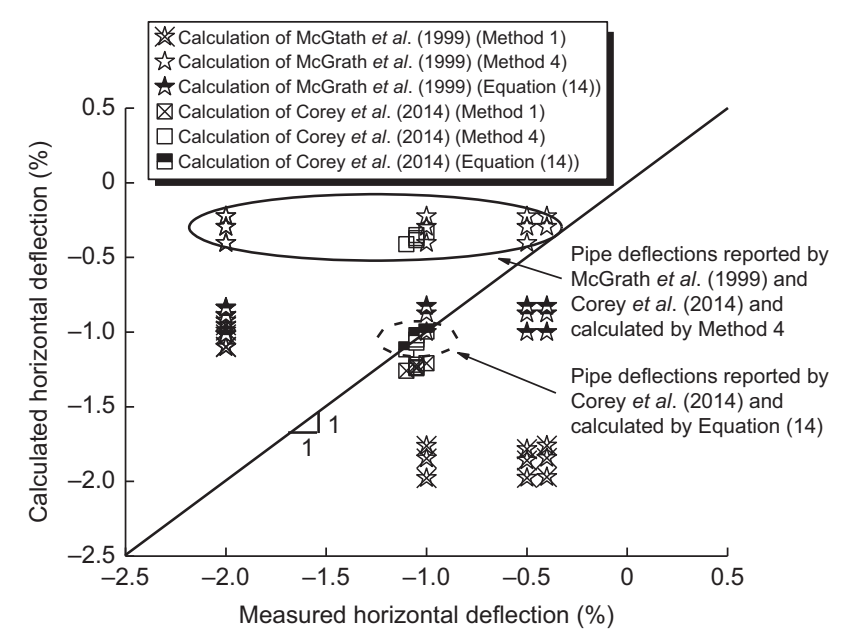

Figure 12. Comparison of the measured and simulated horizontal deflections of pipes for the rammer compactor

Table 3. Values of parameters used for calculation in this study

\begin{tabular}{|l|l|l|l|}
\hline \multirow{2}{*}{ Parameter } & \multicolumn{3}{|c|}{ Value } \\
\cline { 2 - 4 } & P1 pipe & P2 pipe & P3 pipe \\
\hline$D_{\mathrm{o}}(\mathrm{m})$ & 0.69 & 0.69 & 0.34 \\
$\mathrm{PS}(\mathrm{kPa})$ & 215 & 215 & 215 \\
$\mathrm{PS}_{\mathrm{H}}(\mathrm{kPa})$ & 15700 & 15700 & 12700 \\
$M_{\mathrm{s}}^{\mathrm{a}}(\mathrm{MPa})$ & 3.68 & 3.68 & 3.68 \\
$P_{\mathrm{c}}$ & 0.207 & 0.207 & 0.207 \\
$K_{0}$ & 0.47 & 0.47 & 0.47 \\
$B(\mathrm{~m})$ & 2.0 & 2.0 & 2.0 \\
$D_{\mathrm{L}}{ }^{\mathrm{b}}$ & 1.0 & 1.0 & 1.0 \\
$K^{\mathrm{c}}$ & 0.09 & 0.09 & 0.09 \\
$\gamma^{\mathrm{d}}\left(\mathrm{kN} / \mathrm{m}^{3}\right)$ & $18,18.4$ and 19 & $18,18,19.1$ and & 18,18 and 19.1 \\
& & 19.62 & \\
$H(\mathrm{~m})$ & $0.4,0.6$ and 0.9 & $0.2,0.5,1.0$ and & $0.3,0.5$ and 1.0 \\
& & 1.9 & \\
$C_{\mathrm{d}}{ }^{\mathrm{e}}$ & $0.19,0.28$ and & $0.1,0.24,0.46$ and & $0.15,0.24$ and \\
& 0.42 & 0.83 & 0.46 \\
\hline
\end{tabular}

${ }^{\text {a }}$ Recommended by McGrath et al. (1999).

${ }^{b}$ Without consideration of consolidation of the backfill.

${ }^{c}$ Recommended by Moser and Folkman (1990).

${ }^{\mathrm{d}}$ The weighted average unit weight.

${ }^{\mathrm{e}}$ The $k \mu$ value used to calculate $C_{\mathrm{d}}$ in the Marston-Spangler theory is 0.13 in this study.

decrease compared to the undeformed pipe), while those reported by Arockiasamy et al. (2006) were positive (i.e. the diametric increase compared to the undeformed pipe) due to the peaking behaviour of the HDPE pipe (data points circled by a solid line). This phenomenon is also found in Figures 9b and 9c (data points circled by solid line). Compared to the AASHTO (2012) design method, Method 1, Method 2, and Method 4 give a relatively reasonable calculation for the data reported by Arockiasamy et al. (2006). However, the relative errors of these methods are still large (i.e. from $-56 \%$ to $80 \%$ ). From Figures $9 \mathrm{~b}$ and $9 \mathrm{c}$, it is seen that the total deflections in the vertical direction calculated by the Method 1 and Method 2 are 8 to 15 times those measured in tests 13 and 14 reported by McGrath et al. (1999), and are 1.8 to 36 times those measured in this study. The calculations using the proposed method match well with those measured in this study and reported by McGrath et al. (1999) and Arockiasamy et al. (2006). The relative error is less than 10\%, as shown in Figure 9.

Figure 10a shows that the total deflections of the pipe calculated by using Method 1 in the horizontal direction are negative, and are 7 to 8 times those measured in tests 13 and 14 reported by McGrath et al. (1999). The differences between the calculations via Method 4 and the data reported by McGrath et al. (1999) are $25 \%$ to $92 \%$. As seen in Figure 10b, the calculated horizontal deflections of the pipe via Method 1 are positive, and are 2.1 to 43 times the measured ones presented in this study. The predicted horizontal deflections of the pipe via the proposed equation, i.e., Equation 14, match very well with those measured in this study and reported by McGrath et al. (1999). The relative errors are less than $10 \%$, as shown in Figure 10.

\subsubsection{Validation for cases using rammer compactor}

Comparisons of calculations via various methods and experimental data for cases using a rammer compactor are shown in Figures 11 and 12. As seen in Figure 11, the predicted total vertical deflections via the proposed method agree well with the measured data reported by Corey et al. (2014). The relative errors are less than $10 \%$. However, the predicted values are less consistent with the data reported by McGrath et al. (1999). However, as seen in Figure 11, the vertical total deflections calculated using the AASHTO (2012) design method are negative. This method has not considered the effect of the peaking behaviour of the HDPE pipe. The values of pipe deflection predicted using Method 4 are 10\% to $85 \%$ lower than the data reported by McGrath et al. (1999) and Corey et al. (2014). The calculated values of the pipe deflection reported in Corey et al. (2014) using the Method 2 and the AASHTO (2012) design method are not presented, since the hoop stiffness of the pipe is not given in the literature.

Figure 12 shows the comparisons of the total horizontal deflections calculated using Method 1, Method 4 and the proposed method with those reported by McGrath et al. (1999) and Corey et al. (2014). It is seen that the predicted total horizontal deflections using the proposed method agree well with the measured data reported by Corey et al. (2014), with a range of relative error of less than $10 \%$. The calculated values using Method 1 and the proposed method do not agree well with the data reported by McGrath et al. (1999). The horizontal total deflections predicted by Method 4 are $10 \%$ to $95 \%$ lower than the data reported by McGrath et al. (1999) and Corey et al. (2014).

\section{DISCUSSION}

The magnitude of the total deflections of the pipe in both the vertical and the horizontal directions decreased gradually with the increase of the soil cover thickness, 


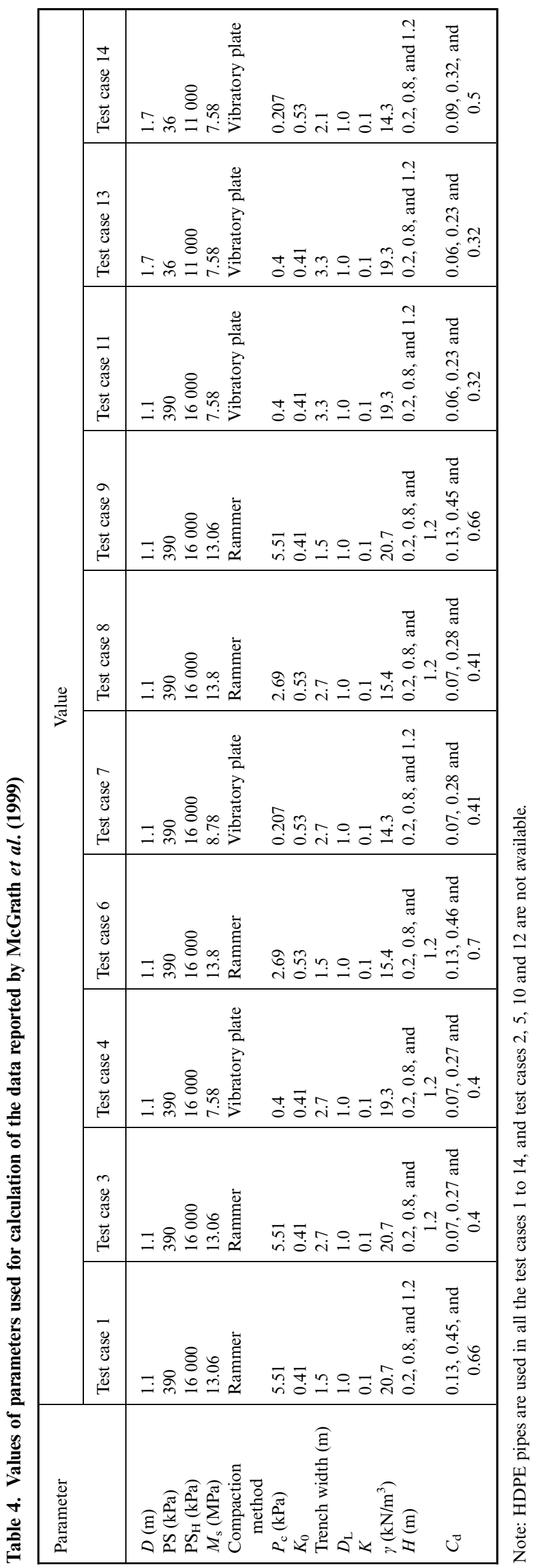

while a small decrease in the pipe deflection was observed when the soil cover thickness was approximately higher than $3 \mathrm{~m}$. (see Figures 3-8). The possible reasons are (1) an increase in the friction force between the backfill and the trench wall with increasing soil cover thickness, and (2) the enhanced ability of the flexible pipe to resist deflection with increasing soil cover thickness. The occurrence of vertical inward deflection of the pipe (i.e. a decrease in the pipe diameter) caused by the overburden earth pressure results in a positive soil arching effect above the pipe, which leads to the transfer of the weight of the soil cover from the top of the pipe to the trench wall. When the soil cover is thin, the friction force along the trench wall is relatively small and only a small portion of the soil cover weight is transferred to the trench wall. However, the friction force increases gradually with an increase in soil cover thickness, and the portion of the weight of the soil cover transferred to the trench wall increases. In the end, the earth pressure acting on the top of the pipe tends to be constant (Moser and Folkman 1990; McGrath et al. 1999). The overburden load of the pipe is calculated using the hoop thrust at the springline of the pipe, as shown in Figure 13. The hoop thrust is obtained from the output results of PLAXIS. Figure 14 shows the variation of the overburden load acting on the pipe (diameter $0.6 \mathrm{~m}$ ) with the burial depth. A pipe stiffness of $215 \mathrm{kPa}$ and sidefill material of SW85 were employed to calculate the overburden load of the pipe by extracting the hoop thrust at the pipe springline. It is seen that the overburden load increased from zero to $24.52 \mathrm{kN}$ when the burial depth increased from zero to $3 \mathrm{~m}$, while a relatively small load increment of $0.96 \mathrm{kN}$ was found when the burial depth increased from $3 \mathrm{~m}$ to $6.9 \mathrm{~m}$. On the other hand, when a flexible pipe is buried in the soil, the pipe and soil then work as a system in resisting the load. A flexible pipe derives its soil-load-carrying capacity from its flexibility. In other words, the vertical load tends to cause a vertical deflection of the pipe, which in turn results in horizontal support from the sidefill (Moser and Folkman 1990). Therefore, the ability of the flexible pipe to resist deflection is expected to increase with an increase in the burial depth. In addition, the total deflection in the vertical direction decreases more significantly with soil cover thickness than that in the horizontal direction. This phenomenon is attributed to the circumferential shortening of the HDPE pipe, with its relatively low pipe hoop stiffness (McGrath et al. 1999; Dhar et al. 2004; McGrath et al. 2009).

The vertical total deflections of the pipe calculated by the AASHTO (2012) design method do not agree well with those reported by Arockiasamy et al. (2006), McGrath et al. (1999), Corey et al. (2014) and this study (Figures 9 and 11). This is attributed to the fact that the peaking deflection of the pipe is not considered in the AASHTO (2012) design method. The total deflections predicted using Method 4 agree well with those measured in this study, while the calculated values do not agree well with the data reported by McGrath et al. (1999) and Arockiasamy et al. (2006) (Figures 9a and 9b and 10a). The possible reason is that only one influencing factor 
Table 5. Values of parameters used for calculation of the data reported by Arockiasamy et al. (2006)

\begin{tabular}{|l|l|l|l|l|l|l|l|l|l|l|}
\hline Parameter & PS $(\mathrm{kPa})$ & $\mathrm{PS}_{\mathrm{H}}(\mathrm{kPa})$ & $M_{\mathrm{s}}^{\mathrm{a}}(\mathrm{MPa})$ & Trench width $(\mathrm{m})$ & $D(\mathrm{~m})$ & $\gamma\left(\mathrm{kN} / \mathrm{m}^{3}\right)$ & $D_{\mathrm{L}}$ & $K$ & $K_{0}$ & $P_{\mathrm{c}}^{\mathrm{b}}(\mathrm{kPa})$ \\
\hline Value & 238 & 18700 & 9.76 & 2.3 & 1.34 & 20 & 1.0 & 0.1 & 0.34 & 0.207 \\
\hline
\end{tabular}

${ }^{\mathrm{a}, \mathrm{b}}$ Recommended by McGrath et al. (1999).

Table 6. Values of parameters used for calculation of the data reported by Corey et al. (2014)

\begin{tabular}{|l|l|l|l|l|l|l|l|l|l|}
\hline Parameter & PS $(\mathrm{kPa})$ & $M_{\mathrm{s}}^{\mathrm{a}}(\mathrm{MPa})$ & Trench width $(\mathrm{m})$ & $D(\mathrm{~m})$ & $\gamma\left(\mathrm{kN} / \mathrm{m}^{3}\right)$ & $D_{\mathrm{L}}$ & $K$ & $K_{0}$ & $P_{\mathrm{c}}{ }^{\mathrm{b}}(\mathrm{kPa})$ \\
\hline Value & 294 & 13.8 & 1.22 & 0.642 & 18.1 & 1.0 & 0.1 & 0.34 & 2.69 \\
\hline
\end{tabular}

Note: steel-reinforced HDPE pipe is used in the laboratory model test.

${ }^{\mathrm{a}, \mathrm{b}}$ Recommended by McGrath et al. (1999).

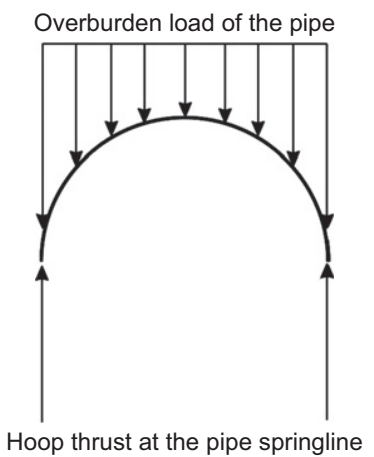

Figure 13. Schematic diagram of calculation of the overburden load of the pipe

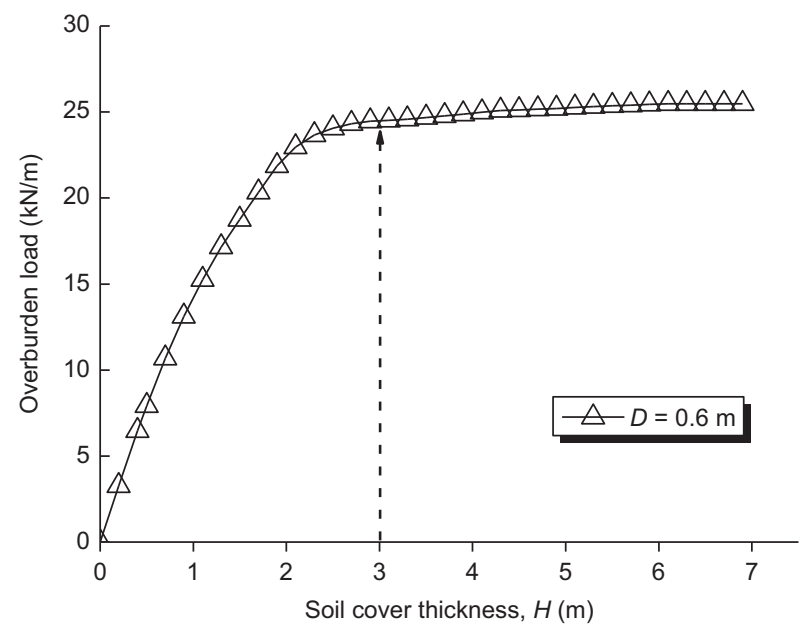

Figure 14. Variation of the overburden load acting on the pipe (diameter of $0.6 \mathrm{~m}$ ) with the burial depth

(i.e. the soil cover thickness) is considered in the method, while the deflections of the pipe are in fact also significantly affected by the relative flexure stiffness and compactor type.

It is noted that in the application of Method 1 and Method 2, 13 parameters are required, i.e., $P_{\mathrm{c}}, K_{0}, \gamma, C_{\mathrm{d}}$, $\gamma^{\prime}, B, D, k \mu, D_{\mathrm{L}}, K, \mathrm{PS}, \mathrm{PS}_{\mathrm{H}}$ and $E^{\prime}$. It is usually hard to estimate the values of most parameters, and they are typically adopted empirically in practice (Moser and
Folkman 1990; McGrath et al. 1999; Masada and Sargand 2007). Meanwhile, the method proposed in this study, i.e., Equations 13 and 14, requires only five parameters, i.e., $S_{\mathrm{f}}, \gamma, H, \eta$ and $D$. The meanings of the five parameters are clear and can be estimated relatively conveniently via conventional soil laboratory tests.

\section{CONCLUSIONS}

2DFE evaluations of the total deflection of the HDPE pipe in both the vertical and the horizontal directions are conducted in this study. The effects of pipe diameter, trench width, pipe stiffness, soil modulus, compactor type, and unit weight of soil cover on the total deflection of the pipe are analysed. Based on the FE results of this study, the following conclusions can be drawn

(1) Because of the circumferential shortening of the HDPE pipe, the magnitude of total deflection of the pipe in the vertical direction decreases with the soil cover thickness more significantly than in the horizontal direction.

(2) The relative flexure stiffness, the type of compactor and the unit weight of soil cover have significant effects on the total deflection of the pipe; meanwhile, the pipe diameter and the trench width have much less significant effects.

(3) Two equations are proposed to predict the total deflections of the HDPE pipe with the consideration of the influence of relative flexure stiffness, compactor type, and unit weight of cover soil. They are

$$
\begin{aligned}
\Delta y / D= & \left(-0.03 S_{\mathrm{f}}+3.4+\left(0.02 S_{\mathrm{f}}+29.6\right)\right. \\
& \times \exp (-\gamma H / 20)) \eta / 10000
\end{aligned}
$$

and

$$
\begin{aligned}
\Delta x / D= & \left(-0.03 S_{\mathrm{f}}+23.4+\left(0.02 S_{\mathrm{f}}+9.6\right)\right. \\
& \times \exp (-\gamma H / 20)) \eta / 10000
\end{aligned}
$$

The proposed equations were verified using the data reported in the literature and the data presented in this 
study. It is demonstrated that the proposed equations improve the accuracy of existing methods. The proposed method also has an advantage over existing methods because it has far fewer parameters and more convenient parameter determination. Therefore the proposed equations are a promising method to predict the total deflection of HDPE pipe in both the vertical and the horizontal directions.

\section{ACKNOWLEDGEMENTS}

The authors are grateful for the financial support from the National Natural Science Foundation of China (Grant No. 51108078, 51278100 and 41472258), Natural Science Foundation of Jiangsu Province (Grant No. BK20131294 and BK2012022), the Fundamental Research Funds for the Central Universities, Colleges and Universities in Jiangsu Province Plans to Graduate Research and Innovation (Grant No. KYLX_0144), and the Scientific Research Foundation of Graduate School of Southeast University (Grant No. YBJJ1632). The authors also express their gratitude to graduate students Q. You, D. D. Dong, and P. C. Wang at Southeast University for their assistance in conducting the field trial.

\section{NOTATION}

Basic SI units are given in parentheses.

$A$ cross sectional area of the pipe wall per unit length $\left(\mathrm{m}^{2} / \mathrm{m}\right)$

$B$ trench width (m)

$C_{\mathrm{d}} \quad$ load coefficient (dimensionless)

$D$ diameter of the pipe (m)

$D_{\mathrm{L}} \quad$ deflection lag factor (dimensionless)

$\mathrm{d} x$ horizontal diameter change/un-deformed pipe diameter (dimensionless)

$\mathrm{d} y \quad$ vertical diameter change/un-deformed pipe diameter (dimensionless)

$E \quad$ Young's modulus of the pipe material $(\mathrm{Pa})$

$E^{\prime}$ modulus of soil reaction $(\mathrm{Pa})$

$H$ soil cover thickness (m)

I moment of inertia of pipe wall per unit length $\left(\mathrm{m}^{4} / \mathrm{m}\right)$

$K$ bedding constant (dimensionless)

$K_{0} \quad$ lateral earth pressure coefficient at rest (dimensionless)

$K_{\mathrm{p}} \quad$ passive earth pressure coefficient (dimensionless)

$k \quad$ active earth pressure coefficient (dimensionless)

$M_{\mathrm{S}} \quad$ constrained soil modulus $(\mathrm{Pa})$

$P_{\mathrm{c}}$ lateral pressure generated by the compactor $(\mathrm{Pa})$

$P_{\mathrm{s}} \quad$ design service pressure $(\mathrm{Pa})$

$P_{\mathrm{sp}} \quad$ soil prism pressure $(\mathrm{Pa})$

PS pipe stiffness (Pa)

$\mathrm{PS}_{\mathrm{H}} \quad$ pipe hoop stiffness (Pa)

$R^{2} \quad$ coefficient of determination (dimensionless)

$r$ radius of the undeformed pipe (m)

$S_{\mathrm{f}} \quad$ relative flexure stiffness (dimensionless)
$W_{\text {c }} \quad$ soil load per unit length of pipe $(\mathrm{N} / \mathrm{m})$

$\gamma$ unit weight of the cover soil $\left(\mathrm{N} / \mathrm{m}^{3}\right)$

$\gamma^{\prime}$ unit weight of the backfill at the lateral side of the pipe $\left(\mathrm{N} / \mathrm{m}^{3}\right)$

$\mu$ coefficient of friction between the backfill and trench wall

$\Delta x$ horizontal diameter change of the pipe (m)

$\Delta y \quad$ vertical diameter change of the pipe (m)

$\varepsilon_{\mathrm{sc}} \quad$ service compressive strain (dimensionless)

$\eta$ an empirical constant related to the compactor type (dimensionless)

\section{ABBREVIATIONS}

2DFE two-dimensional finite-element

AASHTO American Association of State Highway and Transportation Officials

ASTM American Society for Testing and Materials

CECS China Association for Engineering Construction Standardization

CL95 low plasticity clay with a degree of compaction of $95 \%$

HDPE high-density polyethylene

SW85 well-graded sand with a degree of compaction of $85 \%$

SW95 well-graded sand with a degree of compaction of $95 \%$

\section{REFERENCES}

AASHTO (American Association of State Highway and Transportation Officials) (2012). AASHTO LRFD Bridge Design Specifications, 2nd edn. AASHTO, Washington, DC, USA.

Allen, T. M. \& Bathurst, R. J. (1994). Characterization of geosynthetic load-strain behavior after installation damage. Geosynthetics International, 1, No. 2, 181-199.

Arockiasamy, M., Chaallal, O. \& Limpeteeprakarn, T. (2006). Full-scale field tests on flexible pipes under live load application. Journal of Performance of Constructed Facilities, 20, No. 1, 21-27.

ASTM D1556-07 Standard Test Method for Density and Unit Weight of Soil in Place by the Sand-Cone Method. ASTM International, West Conshohocken, PA, USA.

CECS (China Association for Engineering Construction Standardization) (2004). Technical Specification for Buried PE Pipeline of Sewer Engineering. China Association for Engineering Construction Standardization, China Architecture and Building Press, Beijing, China.

Corey, R., Han, J., Khatri, D. K. \& Parsons, R. L. (2014). Laboratory study on geosynthetic protection of buried steel-reinforced HDPE pipes from static loading. Journal of Geotechnical and Geoenvironmental Engineering, 140, No. 6, 04014019.

Dhar, A. S., Moore, I. D. \& McGrath, T. J. (2004). Two-dimensional analysis of thermoplastic culvert deformations and strains. Journal of Geotechnical and Geoenvironmental Engineering, ASCE, 130, No. 2, 199-208.

Fleming, P. R., Faragher, E. \& Rogers, C. D. F. (1997). Laboratory and field testing of large-diameter plastic pipe. Transportation Research Record, 1594, 208-216.

Han, J., Wang, F., Khatri, D., Parsons, R. \& Brennan, J. (2015). Establishing a Design Procedure for Buried Steel-Reinforced High-Density Polyethylene Pipes: A Field Study, Final Report submitted. Kansas Department of Transportation, K-TRAN: KU14-4, Lawrence, KS, USA. 
Hartley, J. P. \& Duncan, J. M. (1987). E' and its variation with depth. Journal of Transportation Engineering-ASCE, 113, No. 5, 538-553.

Howard, A., Spridzans, J. B. \& Schrock, B. J. (1994). Latvia field test of 915-mm fiberglass pipe. In Buried Plastic Pipe Technology: 2nd Volume, STP12662S (Eckstein D. (ed.)). ASTM International, West Conshohocken, PA, USA, pp. 3-21.

Masada, T. \& Sargand, S. M. (2007). Peaking deflections of flexible pipe during initial backfilling process. Journal of Transportation Engineering, 133, No. 2, 105-111.

McGrath, T. J. (1998a). Design Method for Flexible Pipe, A Rep. to the AASHTO Flexible Culvert Liaison Committee. Simpson Gumpertz \& Heger Inc., Arlington, MA, USA.

McGrath, T. J. (1998b). Replacing E' with the constrained modulus in flexible pipe design. In Proceedings of the Pipeline Division Conference (Castronovo, J. P. \& Clark, J. A. (eds)). ASCE, San Diego, CA, USA, pp. 28-40.

McGrath, T. J., Selig, E. T., Webb, M. C. \& Zoladz, G. V. (1999). Pipe Interaction with the Backfill Envelope, FHWA-RD-98-191. National Science Foundation, Washington, DC, USA.

McGrath, T. J., Selig, E. T., Moore, I. D., Webb, M. C. \& Taleb, B. (2002). Recommended Specifications for Large Span Culverts, NCHRP Rep. 473. Transportation Research Board, Washington, DC, USA.

McGrath, T. J., Moore, I. D. \& Hsuan, G. (2009). Updated Test and Design Methods for Thermoplastic Drainage Pipe, NCHRP Report 631. National Cooperative Highway Research Program, National Academy of Sciences Transportation Research Board, Washington, DC, USA.

Mehrjardi, G. T., Tafreshi, S. M. \& Dawson, A. R. (2012). Combined use of geocell reinforcement and rubber-soil mixtures to improve performance of buried pipes. Geotextiles and Geomembranes, 34, 116-130.

Mehrjardi, G. T., Tafreshi, S. M. \& Dawson, A. R. (2013). Pipe response in a geocell-reinforced trench and compaction considerations. Geosynthetics International, 20, No. 2, 105-118.

Moser, A. P. \& Folkman, S. (1990). Buried Pipe Design, 3rd edn. McGraw-Hill Professional, New York, NY, USA

Palmeira, E. M. \& Andrade, H. K. P. A. (2010). Protection of buried pipes against accidental damage using geosynthetics. Geosynthetics International, $\mathbf{1 7}$, No. 4, 228-241.

Rogers, C. D. F. (1988). Some observations on flexible pipe response to load. Transportation Research Board, No. 1191, 1-11.

Rogers, C. D. F., Fleming, P. R., Loeppky, M. W. J. \& Faragher, E. (1995a). The structural performance of profile-wall drainage pipe-stiffness requirements contrasted with the results of laboratory and field tests. Transportation Research Record, No. $1514,83-93$.

Rogers, C. D. F., Fleming, P. R., Loeppky, M. W. J. \& Faragher, E. (1995b). Buried plastic pipe-performance versus prediction. In Proc., Second International ASCE Conference on Advances in Underground Pipeline Engineering (Jeyapalan J. K. \& Jeyapalan M. (eds)), ASCE, Seattle, WA, USA, pp. 248-259.

Sargand, S. M., Masada, T. \& Schehl, D. J. (2001). Soil pressure measured at various fill heights above deeply buried thermoplastic pipe. Transportation Research Record, 1770, 227-235.

Sargand, S. M., Hazen, G. A. \& Masada, T. (2002). Field Verification of Structural Performance of Thermoplastic Pipe under Deep Backfill Conditions, FHWA/OH-2002/023, Final Rep. Ohio Dept. of Transportation, Cincinnati, OH, USA.

Sargand, S. M., Masada, T., Tarawneh, B. \& Yanni, H. (2004). Use of soil stiffness gauge in thermoplastic pipe installation. Journal of Transportation Engineering, 130, No. 6, 768-776.

Shen, S. L., Wu, H. N., Cui, Y. J. \& Yin, Z. Y. (2014). Long-term settlement behavior of the metro tunnel in Shanghai. Tunneling and Underground Space Technology, 40, 309-323.

Spangler, M. G. (1941). The Structural Design of Flexible Pipe Culverts, Iowa State College Engineering Experimental Station, Ames, IA, USA.

Wang, F., Du, Y. J., Zhou, M. \& Zhang, Y. J. (2015). Experimental study of the effects produced by a backfilling process on full-scale buried corrugated HDPE pipes in fine-grained soils. ASCE Journal of Pipeline Systems Engineering and Practice, 7, No. 1, 05015001.

Watkins, R. K. \& Spangler, M. G. (1958). Some characteristics of the modulus of passive resistance of soil: a study in similitude. Highway Research Board Proceedings, Highway Research Board, Washington, DC, USA, vol. 37, pp. 576-583.

Wu, H. N., Shen, S. L., Liao, S. M., \& Yin, Z. Y. (2015a). Longitudinal structural modelling of shield tunnels considering shearing dislocation between segmental rings, Tunneling and Underground Space Technology, 50, 317-323.

Wu, H. N., Shen, S. L., Ma, L., Yin, Z. Y., \& Horpibulsuk, S. (2015b). Evaluation of the strength increase of marine clay under staged embankment loading: a case study, Marine Georesources and Geotechnology, 33, No. 6, 532-541.

Zhou, M., Wang, F., Du, Y. J. \& Liu, M. D. (2017). Performance of buried HDPE pipes. Part I: peaking deflection during initial backfilling process. Geosynthetics International, (accepted).

The Editor welcomes discussion on all papers published in Geosynthetics International. Please email your contribution to discussion@geosynthetics-international.com by 15 February 2018. 